\title{
Construction of a Cognitive Test of Rhythmic Gymnastics for Physical Education Teachers
}

\author{
Samah Hassan Farag Mohamed*
}

The purpose of the research is to design a cognitive test for the teachers of P.E. to measure their cognitive capabilities in Rhythmic Gymnastics; as well as developing standard levels of cognitive testing for the teachers of P.E. the researcher has used the descriptive approach which fits the nature of the research. The community of the research has been selected by the non-random sampling method among the schools of Helwan and cairo governorates; the total number of the schools are 40; 20 school from Cairo and 20 school from Helwan. The research sample has involved 8) P.E. teachers; their ages range between 30 to 47 years old with years of experience not than 5 years. Also, another 20 schools have been selected to conduct the pilot survey; therefore the number of the schools included in the basic sample became 60 schools. The most important results reached by the researcher is the construction of cognitive testing characterized by validity and reliability factors for the Rhythmic Gymnastics to measure the cognitive capabilities of the teachers of P.E., and developing standard levels of cognitive testing.

\section{Introduction}

$\mathrm{T}$ he cognitive domain is of great importance in the field of Physical Education (P.E.). It assists the trainer and teacher to recognize their duties and responsibility, fallen on them, in the field of planning, organizing and evaluating the training process.

measurements in order to determine the scope of development and progress of the training providers where measurement is one of the means of scientific progress. (9:41)

Also, Daniel Charles (2001) has pointed out the need for knowledge as a goal for all educational programs of both fields of teaching and training the curriculums of P.E. He also has pointed out the importance of using cognitive tests to assess the cognitive information for learners. (14:78)

*Lecturer, Ddepartment of Rhythmic Gymnastics Training Exercise, Faculty of Physical Education for Girls, Helwan University, Egypt.
Sports are an essential mean for the progress of nations and honest standard for the level of civilization and renaissance. The gymnastics is one of the most important pillars of sports; especially school sports as it is the scientific way to form a broad base among the young athletes in various sports. Consequently the chances of appearance of sports talents, which is the hope of every nation and its source of pride, expand rather than relying, for the appearance of talents, on chance and at random. Rhythmic gymnastics is one of the branches of gymnastics as it is one of the artistic, creative and competitive sports. It is exercised by female without male as it relies on aesthetic creation and creativity for body movements associated smoothly with accompanying music. Also, the multi- movement performance of Rhythmic gymnastics requires that the athlete to have various mental, physical, psychological and physiological properties that enable the athlete to perform at all levels and with high degree of skill. As for the providers of the training process; whether the trainer or the teacher, 
information, cognitive and training outcome, is required from them which enable them to put the basic components and the technical content for the elements of the body movement (jumps and leaps, pivots, balances, flexibility and waves) that constitute the kinetic sentence and performing the training process in a proper and regulated way. (17)، (24) ، 4 ، $49: 87$ ( 79 ، 7 (25) $21)(18) ،(19) ،(22) ،(25) ،(23)$

Rhythmic gymnastics, as one of the branches of the sports activities, occupies a proper position among the kinetic sports and activities. Also, many local and international tournaments are organized for Rhythmic gymnastics. Schools tournament for Rhythmic gymnastics is one of the local tournaments organized by the Egyptian Gymnastics Federation; on which the schoolgirls; students compete. The player who gets an advanced position can benefit from scoring the marks of sports excellence which are added to the marks of Thanawya Amma (senior year at high school) and therefore rise total marks of the student. The researcher has found out; through attending these tournaments as an international referee for Rhythmic gymnastics, that the majority of these schoolgirls participating don't have neither the capability nor the skill and the knowledge that qualify them for participating and competing in such tournaments to score an advanced position. The researcher also has found out, by discussion with those players, that they are trained by the school teacher unlike the player who scores the first positions and trained on the hands of a trainer who has experience and good knowledge of the sport of Rhythmic Gymnastics. The teacher responsible for the training holds the primary responsibility of instructing the player as well as designing the training plan and the movements' sentences and instructing her towards the optimum performance as well as identifying her mistakes in order to excel at such tournaments and achieving the purpose of participation in such tournaments. Henceforth the dilemma starts to appear before the researcher as she has noticed the low level of the players participating comparing with other players which indicates the poor cognitive and training aspects of the P.E. teachers that are responsible of the training; and consequently reflected on the schoolgirls', participating in tournaments, level.

The Researcher has found out, when reviewing the studies and researches conducted in the cognitive field for the Rhythmic gymnastics and other sports, that all of it were interested in the trainer, player and student and no one has addressed or mentioned the P.E. teacher although a large group of young people fall under his leadership; and those young people can be qualified; selecting from them the talents ones and making then achieve high sports level.

That's why the researcher has discovered the necessity of developing a cognitive testing for the P.E. teacher at girls schools to identify the scope of their informational and cognitive outcome in Rhythmic gymnastics.

The goal: the purpose of the research is to design a cognitive testing for the teachers of P.E. to measure their cognitive capabilities in Rhythmic gymnastics and to develop standard levels for the testing of the P.E. teachers in Rhythmic gymnastics.

\section{The procedures:}

The Approach: The researcher has used the descriptive approach due to its convenience with the nature of the research.

The community: The community of the research has been selected by the non-random sampling method among the schools of Helwan and cairo governorates; the total number of the schools are 40; 20 school from Cairo and 20 school from Helwan. 
The sample: The research sample has involved 80 P.E. teachers; their ages range between 30 to 47 years old with years of experience not than 5 years. Also, another 20 schools have been selected to conduct the pilot survey; therefore the number of the schools included in the basic sample became 60 schools.

Methods of data collecting: The P.E. curriculum of preparatory schools has been reviewed; Attachment (1); as well as the specialized scientific references related to Rhythmic gymnastics, and the tests and measurements. Many Arabic and foreign researches and studies related to the subject of the research have been accounted. Then, the researcher has conducted interviews with P.E. teachers of preparatory schools, specialized professors in the field of Rhythmic gymnastics and international referees for Rhythmic gymnastics. Also, the researcher has designed an opinion poll form for the experts' opinion; Attachment (2).

\section{Steps of Building the test:}

1- Identifying the goal of the test: the primary goal is to reach a tool of a high degree of reliability and validity to identify the cognitive aspects of rhythmic gymnastics for the P.E. teachers.

2- Determining the cognitive levels: the researcher has determined the cognitive levels of the testing by the six levels of Bloom; which are: knowledge, comprehension, application, analysis, synthesis and evaluation; and that due to their convenience with the nature of this study.

3- Determining the axes of the test: after reviewing the curriculum of the P.E. at the preparatory stage, the specialized scientific references and books that dealt with the construction of cognitive tests and the earlier and related studies; the researcher has reached
(5) suggested axes to identify the cognitive abilities of the P.E. teacher in Rhythmic gymnastics. The researcher has reached the following axes thought via those sources:

1-Special Physical preparation

2-Skills preparation

3-Kinetic sentence

4- Certain rules of law

5- Assisting tools/ apparatus in training.

1- Setting the table of specifications: the researcher has designed an opinion poll form includes the (5) suggested axes, attachment (2), to identify the cognitive aspects of the P.E. teachers. It have been presented before (10) experts in order to identify the appropriateness of the proposed axes for measuring the cognitive side in rhythmic gymnastics for teachers of P.E., to make any modification that suit the axis (including addition, merging or modifications), and to determine the relative importance of each axis of the proposed axes. After presentation before the experts, the name of the kinetic sentence axis has been changed to the structuring (formation) of the kinetic sentence, the certain rules of law axis to the generalities of international laws, and the assisting tools in training axis to the legal apparatus for rhythmic gymnastics. Also, the percentage of the experts' opinion id the axes of the test have been determined. Table no. (1) shows the percentage of the experts' views about the proposed axes of the test and its relative importance 
Table (1)The percentage of the experts' views about the suggested axes of the test and its relative importance.

\begin{tabular}{|c|c|c|c|c|c|}
\hline No & Axes of the test & $\begin{array}{c}\text { Percentage } \\
\text { of } \\
\text { approval }\end{array}$ & $\begin{array}{c}\text { Relative } \\
\text { Importance }\end{array}$ & $\begin{array}{l}\text { Relative } \\
\text { weight of } \\
\text { the axis }\end{array}$ & ordering \\
\hline $1-$ & Special Physical preparation & $\% 100$ & $23 \%$ & 25 & 2 \\
\hline $2-$ & Skills preparation & $\% 100$ & $27 \%$ & 29 & 1 \\
\hline $3-$ & Generalities of international law & $\% 100$ & $21 \%$ & 23 & 3 \\
\hline 4- & Statement kinetic structure & $\% 100$ & $16 \%$ & 18 & 4 \\
\hline \multirow[t]{2}{*}{$5-$} & $\begin{array}{l}\text { Legal apparatus for rhythmic } \\
\text { gymnastics }\end{array}$ & $\% 100$ & $13 \%$ & 14 & 5 \\
\hline & Total & & $\% 100$ & 109 & \\
\hline
\end{tabular}

5-Determining the statements of the test (the test in its initial form):

After determining the axes of the test and determining its relative importance according to the experts' opinion; the number of statements of each axis has been calculated. Also, the researcher has chosen the formula of the questions of two types; True and False and the Multi choice questions. The researcher has chosen these two formulas and combined them together so that each type avoids the drawbacks of each other. The first axis has included (15) statements of multi choice and (10) true and false statements. The second axis has included (19) statements of multi choice and (10) true and false statements. The third axis has included (18) statements of multi choice and (5) true and false statements. The fourth axis has included (5) statements of multi choice and (13) true and false statements. The fifth axis has included (9) statements of multi choice and (5) true and false statements.

\section{6-Presenting the test in its initial form before the experts}

The axes have been presented before (10) experts. The researcher has developed the conditions that must be met in the gentlemen
Experts which are; no less than (15) years of the experience in the field of teaching related to the field of the discipline and no less than (10) years of experience in the field of arbitration and training of gymnastics; in order to give their opinion about the extent of convenience of the statements to measure these axes, about the convenience of the statements to the P.E. teachers; and about merging, omitting, modifying and adding what they regard as necessary Attachment (3). (13) statements have been modified while other (16) have been omitted according to the experts' opinions. (4) statements have been omitted from the first axis, (4) from the second, (3) from the third, (3) from the fourth and (2) from the fifth. Therefore the total number of the statements is (93) Attachment (4)

7-The pilot study: the third form of the test has been applied. It consists of (93) questions applied on a sample of (20) schools in order to extract the most convenient statements for the sample of the research and that in the period from 07/05/2009 to 06/11/2009 Attachment (5). The validity of the statements have been counted according to the estimation of its difficulty and easiness and discrimination coefficient. The researcher has accepted the 
statements that meet the following two conditions; difficulty coefficient between (0.3:

0.7 ) and discrimination coefficient greater than
(0.4). Table (3) shows the difficulty and discrimination coefficients of the statements of the test.

Table (3) shows the difficulty and discrimination coefficients of the statements of the test $(n=60)$

\begin{tabular}{|c|c|c|c|c|c|c|c|c|c|c|c|}
\hline No & Difficulty & Easiness & 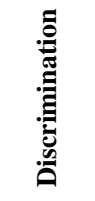 & No & Difficulty & Easiness & 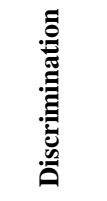 & No & Difficulty & Easiness & 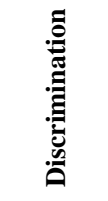 \\
\hline 1 & $\because \leqslant \wedge$ & $\because .0 Y$ & $\because \leqslant V$ & $r r$ & $\because \leqslant 7$ & $\because .0 \leqslant$ & $\because \leqslant \wedge$ & $4 r$ & $\because \leqslant \Lambda$ & $\because$ Or & $\because \leqslant 1$ \\
\hline$r$ & .7 & $\because \varepsilon$ & .71 & $r r$ & .07 & 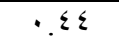 & .71 & $7 \varepsilon$ & $\theta \leqslant Y$ & .01 & .01 \\
\hline$r$ & $\cdot r \varepsilon$ & .77 & .00 & $r \varepsilon$ & $* ., Y \leq$ & $\cdot V 7$ & $\because \leqslant 9$ & 70 &. Or & $\cdot . \leqslant 1$ & .01 \\
\hline$\varepsilon$ & .77 & $\cdot r \varepsilon$ & $.0 \mathrm{~V}$ & ro & ד & $.7 \varepsilon$ & .04 & 97 & 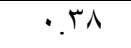 & $\cdot .7 r$ & $\because \leqslant 9$ \\
\hline 0 & $\because 0 \leqslant$ &.$\leqslant 7$ & .01 & ry & $\cdot \varepsilon$ & .7 & .01 & $7 V$ & $\because \leqslant \leqslant$ & .07 & $\because 0 \leqslant$ \\
\hline 9 & $\because .01$ & $\cdot \leqslant r$ & $\because \leqslant 9$ & $r v$ & $\because \leqslant r$ &. .01 & .71 & 71 & $.0 \leq$ &..$\leqslant 7$ & .01 \\
\hline$v$ & $.0 Y$ & 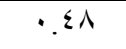 & .77 & $\mathrm{r \Lambda}$ & .7 &.$\varepsilon$ & $\because .0 \mathrm{~V}$ & 79 & $\because \leqslant \varepsilon$ & .07 & .04 \\
\hline$\Lambda$ & $\because \leqslant \varepsilon$ & .07 & $\because \pi r$ & $r q$ & $\because \leqslant \Lambda$ & $\because$ Or & $\because \leqslant \wedge$ & $v \cdot$ & $\cdot \leqslant r$ & .01 & $\because \leqslant 9$ \\
\hline 9 &.$r \varepsilon$ & .77 & $.0 r$ & $\varepsilon$ & $* . r_{7}$ & $\because V \varepsilon$ & .0 & VI & $\ddots \leqslant \leqslant$ & .07 & $\because .01$ \\
\hline 1. & $\because$ Or & $\because \leqslant \Lambda$ & $\because \leqslant 9$ & $\leqslant 1$ &.$\leqslant \leqslant$ & .07 & $.0 \leqslant$ & Vr &.$\varepsilon$ & .7 & .07 \\
\hline 11 &..$\leqslant 7$ & $.0 \leqslant$ & 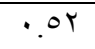 & $\varepsilon r$ & tr. & $\cdot .7 \varepsilon$ & $\cdot . \leqslant 9$ & Vr & $\cdot \leq \leqslant$ & .07 & $\because \leqslant 9$ \\
\hline Ir & .7 & $\cdot \varepsilon$ & $.7 V$ & $\varepsilon r$ & $\cdot r \leqslant$ & .77 & .00 & $V \varepsilon$ & $\because$ Or & $\cdot . \leqslant 1$ & $\because 0 \leqslant$ \\
\hline 14 & $\because \leqslant \varepsilon$ & .07 & *. ro & $\varepsilon \varepsilon$ & $\cdot \leqslant Y$ & .01 & .07 & Vo & $\because$ Or & 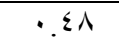 & $\because \leqslant 7$ \\
\hline 18 & $\because 0$ & $\because 0$ & 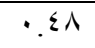 & $\leqslant 0$ & $\cdot \leqslant r$ & .01 & $\because \leqslant 9$ & $V 7$ & $\cdot r \leq$ & .77 & .01 \\
\hline 10 & $* . . \vee 0$ & $\because$ ro & .01 & $\leqslant 4$ & $* ., Y r$ & $\because \vee \wedge$ & $\because \leqslant V$ & $V V$ & $\because \leqslant \Lambda$ & $.0 Y$ & .04 \\
\hline 17 & $\because 0 \leqslant$ & $\because \leqslant 7$ & .77 & $\varepsilon V$ & $\because \leqslant \varepsilon$ & .07 & $\because .0 Y$ & $V \wedge$ & .07 & $\cdot . \leqslant \varepsilon$ & .01 \\
\hline IV & 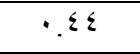 & .07 & 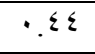 & $\varepsilon \wedge$ &.$\leqslant 7$ & $.0 \varepsilon$ & .07 & Vq & $\because \leqslant 7$ & $.0 \leqslant$ & $\because \leqslant V$ \\
\hline 11 & $\because \leqslant \wedge$ & $\because .0 Y$ & .04 & $\leqslant 9$ & 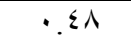 & $\because .0 Y$ & 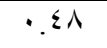 & $\Lambda$. & $\cdot r \varepsilon$ & .77 & 9.07 \\
\hline 19 & $\because .0 Y$ & 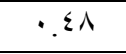 &.$T r$ & 0. & $\because .0 Y$ & $\because \leqslant \wedge$ & $.0 Y$ & $\Lambda 1$ & $\cdot r$ & $\because V$ & .04 \\
\hline$r$. &.$r 0$ & .70 & 0.52 & 01 & $\because \leqslant r$ & .01 & .07 & $\Lambda r$ & $* . .11$ & $\cdot \wedge r$ & .01 \\
\hline$Y 1$ & $\because$ Or & $\because \leqslant \wedge$ & .70 & Or & $\because$ Or & 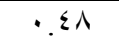 & $\because 0 \leqslant$ & $\Lambda r$ & $* . .1 \leqslant$ & 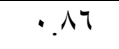 & $\because \leqslant \wedge$ \\
\hline rY & $\ddots^{\circ}$ & $\ddots^{\circ}$ & .09 & or &.$r 0$ & .70 & $* . r \Lambda$ & $\wedge \varepsilon$ & $* .1 \leq$ & $\cdot . \wedge 7$ & $\because \leqslant 9$ \\
\hline$r r$ & $\because \leqslant r$ & .01 & .01 & $0 \leq$ & $\because r 0$ & 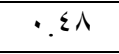 & .01 & 10 & $\cdot \varepsilon$ & .7 & $\because .07$ \\
\hline$r \varepsilon$ & .07 & $\because \leqslant \varepsilon$ & .01 & 00 & $\because$ Or & 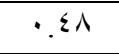 & 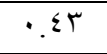 & ᄉ & $* . .1$ & $\cdot .9 \leqslant$ & $.0 r$ \\
\hline ro & $\theta \leqslant 7$ & $\because 0 \leqslant$ & .71 & 09 & $\because 0 \leq$ & $\because \leqslant 7$ & $\because$ Or & $\Lambda V$ & $* .1$ & .9 & .01 \\
\hline Y & $\because \leqslant 7$ & $.0 \leqslant$ & $\because O r$ & $\Delta V$ & $.7 \varepsilon$ & $.0 \leqslant$ & 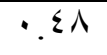 & $\Lambda \wedge$ & $\cdot r r$ & .71 & $* . r v$ \\
\hline$r V$ &.$\leqslant \Lambda$ &.$O Y$ &.$\leqslant \Lambda$ & $\Delta \Lambda$ & $\because 0$ & .0 & .01 & $\wedge q$ & וצ & $.7 \leq$ & .01 \\
\hline$r \wedge$ & $\cdot r$ &.$V$ & .00 & 09 & .07 & $\because \leqslant \varepsilon$ & .01 & 9. & $* . .1 T$ & $\because \wedge \wedge$ & .07 \\
\hline rq & $.7 \pi$ & ד & $.7 \leq$ & 7. & $.0 Y$ &.$\leqslant \lambda$ &.$\leqslant 9$ & 91 &. rᄉ & $.7 Y$ & $\because \leqslant V$ \\
\hline$r$ & $.0 Y$ &.$\leqslant \Lambda$ & $.7 Y$ & 71 & . & .71 &.$O Y$ & 94 &.$\Gamma \varepsilon$ & .97 & $.0 Y$ \\
\hline TI & .00 & .07 & .09 & 97 & $.7 \leq$ & דו & .07 & 94 & $*, r$ &.$\wedge$ & .01 \\
\hline
\end{tabular}

*The following items have been excluded as it lack the required conditions:

The table above shows that the statements of the test meet the difficulty, easiness and discriminations coefficient

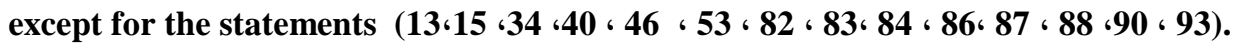


8-The final selection of the statements of the cognitive test: the researcher has made the final selection of the statements of the cognitive test in accordance with the difficulty $\&$ easiness coefficient and discrimination coefficient. (3) statements has been excluded from the first axis; which are (13, 15 and 53). (4) statements has been excluded from the second axis; which are (86, 87, 88 and 90). (3) statements has been excluded from the third axis; which are $(82,83$ and 84). (2) statements has been excluded from the fourth axis; which are (34 and 40) as well as (2) statements from the fifth axis. Therefore the number of the excluded statements is (14) statement and the final form of the test includes (79) statement Attachment (6).

9-Distribution of the statements of the cognitive test: the researcher has re-numbered the statements of the cognitive test from (1: 79). Also, the instructions of the test has been mentioned as well as the method of answering ; and the total mark of the form on the basis that every right answer counts by one and every wrong one counts by (0). Therefore the full mark of the form is (79), and a key to the answers has been developed (Attachment 7).

10- Conducting/ applying the test: the researcher has conducted the test, in its final version/ attachment (6), on the research sample i.e. the teachers of P.E. and their number is (60) teacher in the period from $1 / 7 / 2009$ to $27 /$ 9/2009. Also, the reliability of internal consistency of the test has been calculated. Table ( $4 \& 5$ ) shows the correlation coefficient between the statement and the axis, and the axis and the total mark of the cognitive test.

Table (4) Correlation coefficient between the statement and the axis in the cognitive test $(n=60)$

\begin{tabular}{|c|c|c|c|c|c|c|c|c|c|c|c|}
\hline 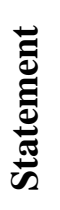 & 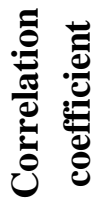 & 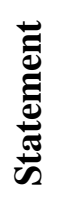 & 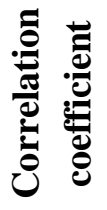 & 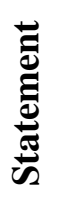 & 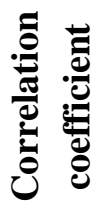 & 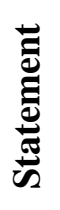 & نَّ & 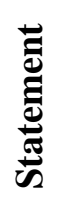 & $\begin{array}{ll} \\
\end{array}$ & 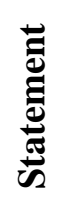 & 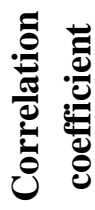 \\
\hline 1 & .01 & $1 \varepsilon$ & .00 & $r V$ & $.0 \leqslant$ & $\varepsilon$. &.$\leqslant 7$ & Or & .71 & 77 & $.0 \leqslant$ \\
\hline r & .07 & 10 & זד. & $r \wedge$ &.$T Y$ & $\{1$ & $.7 r$ & $0 \leq$ & .0 & $7 \mathrm{~V}$ & .71 \\
\hline$r$ & $.0 \leq$ & 17 &.$V Y$ & rq & $.0 \mathrm{~V}$ & $\varepsilon Y$ & וT & 00 & . & 71 &.$V Y$ \\
\hline$\varepsilon$ &. & iv & .70 & r. & .79 & $\varepsilon r$ & .01 & 07 &.$\leqslant 7$ & 79 & .70 \\
\hline 0 &.$\leqslant 9$ & 11 & .01 & I & $.7 V$ & $\leq \varepsilon$ & $\because \leqslant 9$ & $\Delta V$ & $.0 r$ & $V$. & .0 \\
\hline 7 & .0 & 19 &.$\leqslant \wedge$ & $r r$ & .00 & $\leqslant 0$ & . r & $\Delta \wedge$ & $.0 V$ & VI & .01 \\
\hline V & $.7 r$ & $r$. & . & rr & .01 & $\varepsilon 7$ & .07 & 09 & $.7 \varepsilon$ & $V Y$ & .49 \\
\hline$\Lambda$ & .00 & YI & $.0 Y$ & $r \varepsilon$ & .71 & $\varepsilon V$ &.$V I$ & 7. & 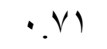 & Vr & $.0 \leqslant$ \\
\hline 9 & . & $r Y$ & $.7 V$ & ro &.$\leqslant V$ & $\varepsilon \wedge$ &.$\vee \wedge$ & 71 & .79 & $V \varepsilon$ & .71 \\
\hline 1. & .01 & $r r$ & $.0 \mathrm{~V}$ & rq &. Or & $\varepsilon 9$ & $.7 r$ & $7 r$ & $\because V \varepsilon$ & vo & שT. \\
\hline 11 &..$\leqslant \wedge$ & $Y \varepsilon$ &..$\leqslant \wedge$ & $r v$ &.$\leqslant 9$ & 0. & $.0 \leqslant$ & Tr & .77 & $V 7$ & .07 \\
\hline Ir &.$\leqslant \wedge$ & ro & .71 & $r \wedge$ & .01 & 01 &.$r V$ & $7 \varepsilon$ & $.0 Y$ & $V V$ & $.0 \leqslant$ \\
\hline ir & $.0 Y$ & Y & .00 & rq & . & or & $.0 \leq$ & 70 & דr. & $\vee \wedge$ & .01 \\
\hline
\end{tabular}

The indexed value $(r)$ at the intangible level $(0.05)=(0.250)$. The above table shows that there is a statistically significant correlation between the mark of each statement and the total number of axis which shows the reliability of the test in measuring what it was meant to measure. 
Table (5)The correlation coefficient between the axis and the total mark of the cognitive test $(n=60)$

\begin{tabular}{|l|c|c|c|}
\hline \multicolumn{1}{|c|}{ Axes of the test } & $\begin{array}{c}\text { Correlation with the } \\
\text { total mark }\end{array}$ & Axes of the test & $\begin{array}{c}\text { Correlation with } \\
\text { the total mark }\end{array}$ \\
\hline Special Physical preparation & $\ddots V T$ & Structure of kinetic sentence & $.7 r$ \\
\hline Skill preparation & $\ddots \Upsilon 1$ & $\begin{array}{c}\text { Legal apparatus for } \\
\text { rhythmic gymnastics }\end{array}$ & $\ddots 70$ \\
\hline Generalities of international law & $\ddots 7 V$ & & \\
\hline
\end{tabular}

The indexed value $(r)$ at the intangible level $(0.05)=(0.250)$. The above table shows that there is a statistically significant correlation between the mark of each statement and the total number of axis which shows the reliability of the test in measuring what it was meant to measure.

\section{Validity of the test:}

to calculate the degree of validity, the researcher has the method of conducting the test then re -conducting it and finding the correlation coefficient between the first and the second conducting. Table (6) shows the correlation coefficient first and the second conducting of the cognitive test.

Table (6) the reliability by the split half method for the axes of the cognitive test. $(n=60)$

\begin{tabular}{|c|c|c|c|c|c|}
\hline No. & Statistical correlation & Value & No. & Statistical correlation & Value \\
\hline$\checkmark$ & $\begin{array}{c}\text { The link between the two } \\
\text { parts }\end{array}$ & $\cdot \vee r$ & $r$ & $\begin{array}{c}\text { The number of statements in } \\
\text { part two }\end{array}$ & $\varepsilon$ \\
\hline$r$ & $\begin{array}{c}\text { The number of statements } \\
\text { in the first part }\end{array}$ & $r q$ & $\varepsilon$ & Reliability coefficient & $\bullet . \wedge r \varepsilon$ \\
\hline
\end{tabular}

The indexed value (r) at the intangible level $(\mathbf{0 . 0 5})=(\mathbf{0 . 2 5 0})$. The above table shows that there is a statistically significant correlation between the two parts of the cognitive test (the single and the double statements) which indicates the reliability of the testing.

The percentile degrees of the test: the researcher has used the percentile degrees as one if the statistical methods; in order to set standards for the cognitive test of the teachers of the P.E. in Rhythmic gymnastics. After developing the final version of the cognitive test; the researcher has developed criteria for the raw test marks scores and the percentiles corresponding to it; in order to achieve the second goal of the test. Table (7) shows the scores of the test (the value) and the corresponding percentile for each value. 
Table (7) Standard/ criteria of the test

\begin{tabular}{|c|c|c|c|c|c|c|c|}
\hline Value & $\begin{array}{c}\text { Percent(perce } \\
\text { ntile score) }\end{array}$ & Value & $\begin{array}{c}\text { Percent(perc } \\
\text { entile score) }\end{array}$ & Value & $\begin{array}{c}\text { Percent(perce } \\
\text { ntile score) }\end{array}$ & Value & $\begin{array}{c}\text { Percent(perce } \\
\text { ntile score) }\end{array}$ \\
\hline 32.55 & $\% 5$ & 36.30 & $\% 30$ & 41.00 & $\% 55$ & 45.80 & $\% 80$ \\
\hline 33.00 & $\% 10$ & 37.00 & $\% 35$ & 42.00 & $\% 60$ & 46.00 & $\% 85$ \\
\hline 33.65 & $\% 15$ & 37.00 & $\% 40$ & 43.15 & $\% 65$ & 49.70 & $\% 90$ \\
\hline 36.00 & $\% 20$ & 38.00 & $\% 45$ & 44.00 & $\% 70$ & 52.25 & $\% 95$ \\
\hline 36.00 & $\% 25$ & 40.50 & $\% 50$ & 45.00 & $\% 75$ & 58.00 & $\% 100$ \\
\hline
\end{tabular}

The following table shows that the minimum raw score is (32.5) and its corresponding percentile degree is (5\%) while the maximum raw score is $(\mathbf{5 8})$ and its corresponding percentile degree $(\mathbf{1 0 0 \%})$. The researcher has suggested the following levels for the scores of the cognitive exam. Table (8) Levels of the cognitive test

\begin{tabular}{|c|c|c|c|c|c|}
\hline No. & Percentage & Grade & No. & Percentage & Grade \\
\hline 1 & $\% \circ$ & Acceptable & $r$ & $\% \vee 0$ & Very Good \\
\hline$r$ & $\% \% 0$ & Good & $\varepsilon$ & $\% \wedge \circ$ & Excellent \\
\hline
\end{tabular}

\section{Conclusions:}

1- A cognitive testing has been constructed in Rhythmic gymnastics to measure the cognitive capabilities of the physical education teachers. The test has included (79) statements distributed among (5) main axes:

- Special Physical preparation

- Skill preparation

- Generalities of international law

- Structure of the kinetic sentence

- The legal apparatus of the Rhythmic gymnastics

2- The instruction of test has been determined.

3- A key to the correction of the answers has been set

4- The ability of the test to measure the cognitive side for the P.E. teachers in rhythmic gymnastics as the testing was characterized by validity and reliability coefficients.
5- Developing standard levels for the cognitive test.

\section{References:}

1-Samia Ahmed Kamel Elhgrass (2004): Rhythmic exercises and Rhythmic Gymnastics Scientific and technical concepts, library and printing press ElGhad, I(1).

2-Enayat Labib, Baraksan Osman (2001): Exercises and Rhythmic Gymnastics, Cairo.

3-Laila Farhat (2001): The measuring Cognitive athletics, book publishing center, 1, Cairo.

4-Daniel .S \& Charles Kin (2001) : Knowledge For Teaching Physical Education\& Coaching, New York, Everest House.

5 -

batal.com/vb/images/imgup/322_1166957509..jpg

6-http://www. ar.wikipedia.org/wiki/

7-http://www. alumniyat.com/.../17224

8-http://www. madfifa.maktoobblog.com/.../

9-http:// WWW. masrawysyana.com/vb/archive/index.php/t-80.ht 10-http:// www.raya.com/site/topics/article.asp?cu.. 11-http://www .wrod.cinebb.com/montada-f18/to 
